\title{
Three dimensional imaging of electrical trees in multiple stages
}

\section{Document Version}

Accepted author manuscript

Link to publication record in Manchester Research Explorer

\section{Citation for published version (APA):}

Chen, S., Lv, Z., Rowland, S., Withers, P., \& Carr, J. (2018). Three dimensional imaging of electrical trees in multiple stages. In IEEE Conference on Electrical Insulation and Dielectric Phenomena (CEIDP)

\section{Published in:}

IEEE Conference on Electrical Insulation and Dielectric Phenomena (CEIDP)

\section{Citing this paper}

Please note that where the full-text provided on Manchester Research Explorer is the Author Accepted Manuscript or Proof version this may differ from the final Published version. If citing, it is advised that you check and use the publisher's definitive version.

\section{General rights}

Copyright and moral rights for the publications made accessible in the Research Explorer are retained by the authors and/or other copyright owners and it is a condition of accessing publications that users recognise and abide by the legal requirements associated with these rights.

\section{Takedown policy}

If you believe that this document breaches copyright please refer to the University of Manchester's Takedown Procedures [http://man.ac.uk/04Y6Bo] or contact uml.scholarlycommunications@manchester.ac.uk providing relevant details, so we can investigate your claim.

\section{OPEN ACCESS}




\title{
Three dimensional imaging of electrical trees in multiple stages
}

\author{
S. Chen ${ }^{1}$, Z. Lv ${ }^{1}$, S. M. Rowland ${ }^{1}$, J. Carr ${ }^{2}$ and P. J. Withers ${ }^{2}$ \\ ${ }^{1}$ School of Electrical and Electronic Engineering, ${ }^{2}$ School of Materials \\ The University of Manchester \\ s.rowland@manchester.ac.uk
}

\begin{abstract}
Electrical trees are degraded paths in polymeric insulation and are the mechanism of electrical failure of high voltage insulation systems. Previous studies have confirmed the application of X-ray Computed Tomography (XCT) imaging of electrical trees using phase contrast enhancement. This work evaluates the feasibility of $\mathrm{X}$-ray imaging of electrical trees to measure growth at several stages of growth in the same treeing sample. The impact of $x$-ray dose on the epoxy resin studied is determined experimentally. An example of multi-stage tree imaging using laboratory micro-XCT and reconstructed renderings is provided. Based on the three-dimensional tree models, characteristics such as the degraded volume and surface area can be quantified. Furthermore, a comparison between two stages is presented to show the growth of the electrical tree in a fixed period of time. Insight into the treeing characteristics is also discussed.
\end{abstract}

Key words-electrical trees, 3D, tree-dimensional imaging, $X$ ray, tensile tests, FTIR, multiple stages

\section{INTRODUCTION}

Electrical trees are regarded as a main cause of electrical breakdown in high voltage (HV) solid polymeric insulation systems. The treeing phenomenon is normally seen under high electrical fields, and is associated with partial discharge (PD) activity, thought to be a driving force damaging the polymeric materials. Collectively the resulting degraded channels through the polymer present visual structures resembling botanical trees. The basic mechanisms of tree generation and growth are still not totally clear. Research in this area will directly contribute to the management of high voltage plant and improved insulation design.

Research on the growth characteristics of tree structures can link the morphology of electrical trees to PD activity [1]. Growth behavior can be analyzed considering features such as growth rate [4], fractal dimension [2, 3] and expansion coefficient (D/L) [5]. However, most analysis is limited by the availability of images in two dimensions only, and the analysis is restricted by the quality of the corresponding $2 \mathrm{D}$ imaging technique. Tree images are typically projections of the tree onto a two dimensional surface, or projections of 'slices' of tree, the thickness of which are determined by the depth of field of the imaging equipment. Thus the images may not present the complete structure, or clarity desired. An additional difficulty of tree imaging is the resolution of imaging may not provide representation of the detail microscopic structure, and the internal structure may be hidden by external features. Also electrical trees can spread, so that peripheral details can be missing from an image.

The first application of 3D imaging to treeing studies was introduced in [6] and gave a clear relationship between fractal dimension $\mathrm{D}_{\mathrm{f}}$ and tree structures: $1<\mathrm{D}_{\mathrm{f}}<2$ for a 'branch' tree and $2<D_{f}<3$ for 'bush' trees. The imaging system used in [6] was achieved by a serial sectioning method (SSM), resulting in a limited resolution of $25 \mu \mathrm{m}$.

More recently, three high-resolution systems for visualization and generation of $3 \mathrm{D}$ electrical trees have been developed exploiting developments in X-ray techniques and electron microscopy [7, 8]. Serial Block-Face Scanning Electron Microscopy (SBFSEM) has the same basic mechanism as the serial sectioning method (SSM) in [6] but can provide an improved resolution $(\sim 50 \mathrm{~nm})$. However a major disadvantage of SBFSEM is that it destroys the object being examined. As a non-destructive technique, XCT can provide more opportunities for repeatable analysis. The microXCT technique, which can examine a cylindrical sample with a diameter up to $3 \mathrm{~mm}$, can reveal the entire 3D tree structure with sub-micron resolution (less than $0.5 \mu \mathrm{m}$ ). The nano-XCT has a similar resolution to SBFSEM but the maximum field of view is limited to a diameter of $0.5 \mathrm{~mm}$. For this reason it is mainly applied for examining pre-dissected samples, and so must be regarded as a destructive technique in this context.

This paper discusses the feasibility of multi-stage treeing experiments, the purpose being to develop a technique which generates images of a tree as it grows. The micro-XCT system was used to ensure the whole tree pattern was captured, and to allow growth of the tree between imaging events. Such a technique requires repeated exposure to high X-ray doses, so an assessment of the impact of X-ray irradiation on epoxy resin was also carried out. The reconstructed renderings of a single electrical tree at two moments in its development are introduced and discussed.

\section{EXPERIMENTAL}

\section{A. To determine the impact of $X$-rays on epoxy resin}

Tensile tests and Fourier Transform Infrared Spectroscopy (FTIR) were carried out after exposure to controlled doses to give quantitative assessment of the impact of X-rays on the 
epoxy resin. Four groups of dumbbell samples (with an exposed cross-sectional area of $10 \mathrm{~mm}^{2}$ ) were divided according to different $\mathrm{X}$-ray sources and exposure times. The control Group A comprised 15 samples, which were not exposed to radiation. Each irradiated group B, C, and D consisted of 5 samples. Samples from Group B and C were exposed in a 320 Nikon Custom Bay system for 80 mins and 160 mins respectively. Samples from Group D were exposed in a TH 225 WIR for 160 mins. All radiated samples were exposed to X-ray sources at $150 \mathrm{keV}$ and $125 \mathrm{~W}$ with $30 \mathrm{~mm}$ source-to-detector distance. The high voltage ensured high $\mathrm{X}$ ray intensity so as to maintain a similar energy in a shorter period, compared with the $110 \mathrm{KeV}$ of the micro XCT facility introduced below. After irradiation, samples were tensile tested on an Instron 8802.

\section{B. To develop three dimensional replicas of trees}

A conventional needle-to-plane configuration was employed with a distance of $2 \mathrm{~mm}$ between the needle tip and the earthed base of the sample. A room-temperature curing epoxy resin system (Huntsman Araldite ${ }^{\circledR}$ LY 5052 and Aradur® HY 5052) was used for sample preparation. A steel needle (Ogura Jewel ${ }^{\circledR}$ ) with a $3 \mu \mathrm{m}$ tip radius and $30^{\circ}$ taper angle was used as the needle electrode to stimulate the tree. A $2 \mathrm{~mm}$ diameter cylinder was machined around the needle tip to meet the needs of the X-ray imaging technique. During the electrical testing, the sample was immersed in degassed silicon oil to avoid surface discharges. For the first stage of the test, the sample was energized at $10 \mathrm{k} V_{\text {rms }}$. The whole treeing experiment was monitored by a CCD camera. After the electrical tree initiated and propagated to a length of $115 \mu \mathrm{m}$, the voltage was removed. The micro-XCT system in the Manchester X-ray Imaging Facility (MXIF) has been introduced in [7]. The XCT Versa-520 system has a 0.2382 $\mu \mathrm{m}$ pixel size and the voltage was set at $110 \mathrm{KeV}$. Phase contrast was applied to obtain a sufficient contrast between the polymeric material and internal (hollow) features. The Xray scanning lasted about 36 hours. For the second stage, the same energizing-and-imaging cycle was repeated, but the treeing voltage was decreased to $6 \mathrm{kV}$ for 3 minutes to slow

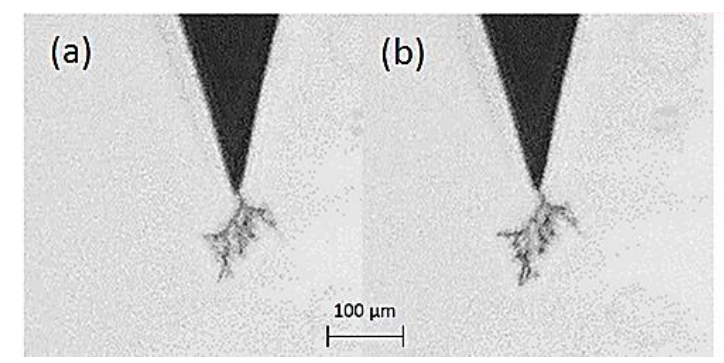

Figure 1: Optical images of (a) the first-stage tree grown at $10 \mathrm{kV}$ for 10 minutes; (b) the second-stage tree grown at $6 \mathrm{kV}$ for a further 3 minutes. down the propagation of the electrical tree. During this period the tree structure extended $6.3 \mu \mathrm{m}$ in the vertical direction. The images from both stages are shown in Figure 1.

\section{RESULTS AND DISCUSSION}

\section{A. The impact of $X$-rays on epoxy resin}

After exposure to X-rays, samples turned from a light yellow to a darker amber colour, which was also found in the sample after imaging. However the samples still remained transparent.

The mean breakdown stress for unexposed group is 43.13 $\mathrm{MPa}$ and the deviation of the three irradiated groups from this is $-13.43 \%,-8.27 \%$ and $+9.5 \%$ respectively. Considering sample to sample variation, the comparison in Figure 2 does not show a meaningful difference in terms of mechanical properties. Damage in the form of cross-linking increasing tensile strength or chain scission reducing strength is not evident.

FTIR was applied to compare the compositional characterization on the discoloured surface. One sample each from Groups B (80 mins) and C (160 mins) were selected, and compared to two samples from the control group. The results are shown in Figure 3.

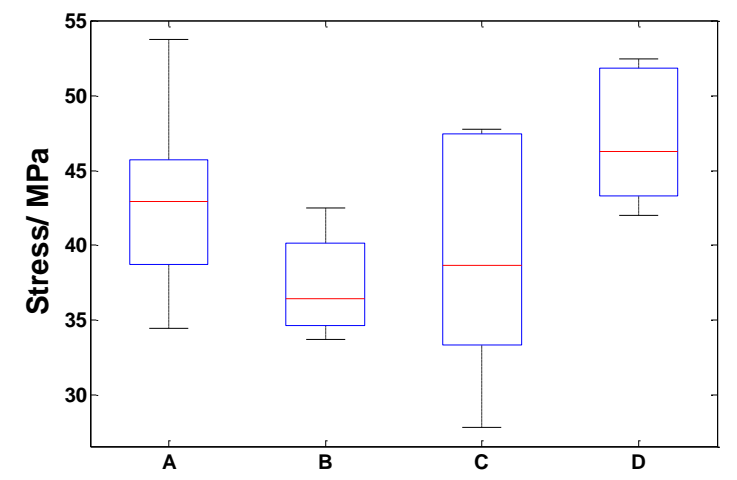

Figure 2: Tensile strengths of epoxy resin with exposures of: (A) 0 mins; (B) 80 mins; (C) 160 mins; (D) 160 mins.

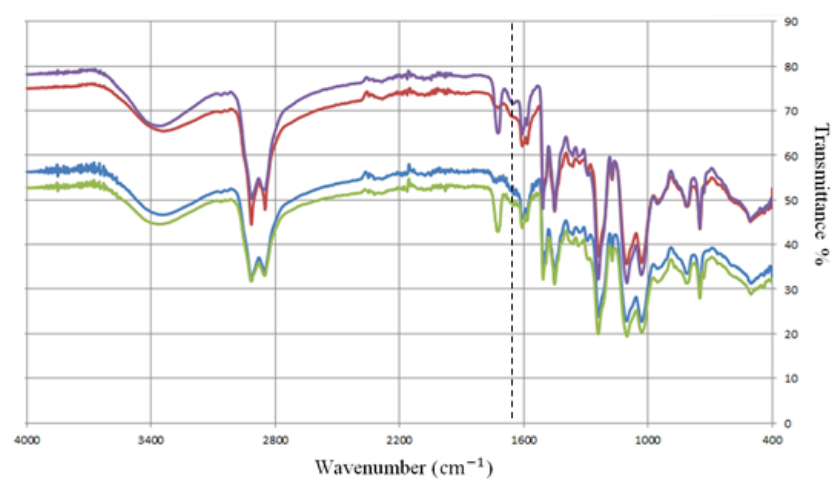

Figure 3: FTIR transmittance spectra of samples from: Group A in green and blue (lower lines), and Groups B in red and C in purple (higher lines). 
The difference in transmittance amplitude seen in figure 3 arises from the variation of sample thickness. Regardless of the magnitude however, these four spectra have similar patterns. Typical peak positions do not have a shift in wavenumbers because the few key chemical groups were not modified. An additional vibration at $1658 \mathrm{~cm}^{-1}$ is found in both irradiated samples (red and purple). This peak corresponds to Alkene $(\mathrm{C}=\mathrm{C})$ stretches of aromatic rings [11]. It is well documented that discoloration of polymers can result from high-intensity light (particularly in the UV region) or thermal damage $[12,13]$. For photo-oxidation, the variation of some UV-sensitive groups such as aromatic groups may be significant. Results here suggest a pre-stage oxidation may have started.

Overall, the results above show that there is little change in the epoxy resin due to irradiation. Discoloration did occur but the aging was only taking place on the polymer surface, and so there is no evidence of change the bulk properties. It is possible that the material damaged by PD in the vicinity of the tree, after a period of tree growth [14], may be more susceptible to x-ray damage than the rest of the epoxy. However that requires much more detailed study than has been possible to date.

\section{B. Reconstruction of multiple trees}

The two-stage 3D imaging was conducted using 1892 slices with a voxel size of $0.2382 \mu \mathrm{m}$, collected from microXCT system, which presents a $6.9 \times 10^{7} \mu \mathrm{m}^{3}$ cylinder. A subvolume of $135.7 \mu \mathrm{m} \times 138.1 \mu \mathrm{m} \times 111.8 \mu \mathrm{m}$ was extracted for detail processing. Before the generation of the tree model, both datasets were optimized by Avizo image processing software. In order to increase the signal-to-noise ratio without removing artifacts, only a median filter was applied in this case. Then segmentation was carried out to generate the final models. As shown in Figure 4, virtual replicas for each stage were reconstructed with the same processing methods.

In Figure 4(a), (b) and (c) the models for each stage have been normalized so that new characteristics in the second stage could be easily identified. The $2 \mathrm{D}$ projection image in Figure 4(d) shows, what appears to be an air gap covering the needle tip. This feature cannot be seen by normal optical methods. As measured, the tip radius of the needle shape void presented by the air gap was $1.85 \mu \mathrm{m}$ which is smaller than the needle $(3 \mu \mathrm{m})$. The tree (black strips in Figure 4(d)) appears to be initiated from the tip of the air gap, not directly from the metallic needle tip. The size of the air gap did not change during the treeing process. It can be inferred that as the electrical tree started to grow there was no further damage in the air gap, which suggests the majority of the PDs freely pass through the air gap and into tree channels. The importance of

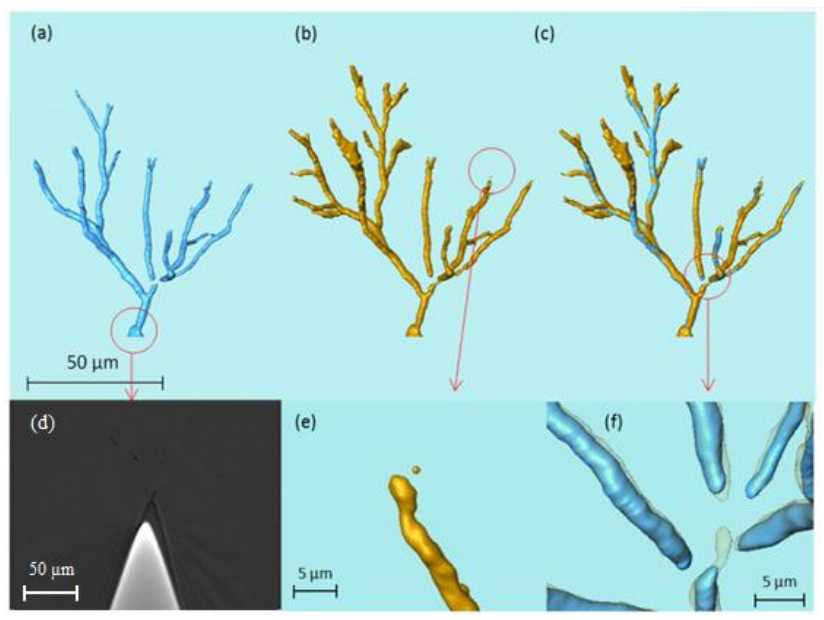

Figure 4: (a) 3D rendering of first-stage tree; (b) 3D rendering of secondstage tree; (c) overlapped rendering of both stages; (d) ortho slice around the needle; (e) detached void found over a tree channel in the first reconstruction; (f) disconnections in the overlapped rendering with the second stage presented in a lighter tone.

such a gap and movement of gas between the needle and polymer has been discussed previously [15].

One of the most helpful contributions of the 3D imaging is that the real tree structure can be quantified. Some global and structural parameters are shown in Table 1.

In the first-stage model, 13 bifurcations are found and the divergence angle varies from $34.2^{\circ}$ to $74.5^{\circ}$. And for the second-stage, 6 more bifurcated channels are generated and the maximum diverging angle increases to $93.4^{\circ}$. With energizing for 3 mins, the top branch grew $9.2 \%$, which is the fastest growth rate $(0.06 \mu \mathrm{m} / \mathrm{s})$ in the whole structure. There are four branches growing less than $1 \%$ and all of them are located at what appear to be disconnected branches (as seen in the right-hand part in Figure 4(a)). There is little change to the tree root diameter between stages.

Table 1: Global and structural parameters of the tree

\begin{tabular}{ccc}
\hline & $1^{\text {st }}$ stage & $2^{\text {nd }}$ stage \\
\hline \hline Number of Tips & 16 & 24 \\
Longest branch $(\mu \mathrm{m})$ & 118.48 & 129.44 \\
Surface Area $\left(\mu \mathrm{m}^{2}\right)$ & 3861.74 & 5975.9 \\
Volume $\left(\mu \mathrm{m}^{3}\right)$ & 2286.79 & 3839.55 \\
Convex Hull Volume $\left(\mu \mathrm{m}^{3}\right)$ & 195432 & 299521 \\
Root Diameter $(\mu \mathrm{m})$ & 3.08 & 3.12 \\
Diameter Max $(\mu \mathrm{m})$ & 5.01 & 7.64 \\
3D Fractal Dimension & 1.66 & 1.72 \\
\hline
\end{tabular}


The 'degraded proportion' is defined as the ratio between tree volume and convex hull volume (the convex volume which encloses the tree channels and touches their extreme points). It is $1.17 \%$ and $1.28 \%$ for each stage respectively. The surface-to-volume ratio decreases from 1.689 to 1.556 $\left(\mu \mathrm{m}^{-1}\right)$ during the growth. Both stages can be regarded as typical branch tree structures according to the fractal dimension value of $\sim 1.7[6,10]$.

Discontinuities in the structure as shown in Figure 4(e) and (f) were found at both stages. It is possible that these branches are connected to the main tree by features smaller than the resolution of the imaging technique. Due to their different morphologies, they are divided into two categories: Firstly, massive disconnections as shown in Figure 4(f), which may result from some internal defects, such as winding structures or solid impurities filling the tree channel. These discontinuities usually suggest a connective trend towards the trunk and so are considered parts of the main tree structure. In contrast, some freestanding disconnections, for example the void shown in Figure 4(e), seem to be more independent of main tree channels. Similar features have also been reported in DC trees [9] and in that case were regarded as pre-tree stages of degradation. These structures are mainly $\mu \mathrm{m}$-sized voids around the electrical tree and may suggest a new mechanism for tree growth. More work is required to understand the fundamental quality of X-ray imaging and image processing to ensure a clear interpretation of such data.

\section{CONCLUSION}

For the two stages considered, it has been shown that the $\mathrm{X}$-ray radiation for $3 \mathrm{D}$ imaging does not damage the material being studied. However surface oxidation does indicate early signs of ageing is present. As a result the multi-stage XCT imaging and reconstruction can be considered reflective of 'normal' tree growth.

The XCT imaging of an electrical tree twice at close intervals during its growth disclosed detailed structural variation as the tree grew. Parameters reflecting the tree size, such as length, volume and surface area were shown to increase. Parameters reflecting morphology, such as fractal dimension did not change, but that is to be expected given the small increment of growth examined.

The technique can provide excellent capabilities to study the development of 3D tree characteristics in more details, including small, apparently disconnected voids at the tree tip.

\section{REFERENCE}

[1] C. Laurent and C. Mayoux, 'Analysis of the Propagation of Electrical Treeing Using Optical and Electrical Methods' IEEE Transactions on Electrical Insulation, vol. EI-15, no. 1, pp. 33-42, 1980

[2] S. Maruyama, S. Kobayashi, K. Kudo, 'Three-dimensional reconstructed image of electrical tree using serial sectioning method and its fractal characteristics, IEEJ Transactions on Fundamentals and Materials', 114(1), pp. 47-52, 1994

[3] L. A. Dissado, 'Fractal processes and Weibull statistics' International Conference on Conduction and Breakdown in Solid Dielectrics, Trondheim, 1989, pp. 538-532

[4] M. Bao, X. Yin, J. He, 'Structure characteristics of electrical treeing in XLPE insulation under high frequencies', Physica B: Condensed Matter, 406(14), pp. 2885-2890, 2011

[5] X. Zheng and G. Chen, 'Propagation mechanism of electrical tree in XLPE cable insulation by investigating a double electrical tree structure' IEEE Transactions on Dielectrics and Electrical Insulation, vol. 15 , no. 3, pp. 800-807, 2008

[6] S. Kobayashi, S. Maruyama, H. Kawai and K. Kudo, 'Estimation of 3D fractal dimension of real electrical tree patterns', International Conference on Properties and Applications of Dielectric Materials (ICPADM), Brisbane, 1994, pp. 359-362

[7] R. Schurch, S. M. Rowland, R. S. Bradley and P. J. Withers, 'Comparison and combination of imaging techniques for three dimensional analysis of electrical trees', IEEE Transactions on Dielectrics and Electrical Insulation, vol. 22, no. 2, pp. 709-719, 2015

[8] R. Schurch, S. M. Rowland, R. S. Bradley and P. J. Withers, 'Imaging and analysis techniques for electrical trees using X-ray computed tomography', IEEE Transactions on Dielectrics and Electrical Insulation, vol. 21, no. 1, pp. 53-63, 2014

[9] L. K. H. Pallon, F. Nilsson, et al. 'Three-Dimensional Nanometer Features of Direct Current Electrical Trees in Low-Density Polyethylene', Nano Letters 17(3): pp. 1402-1408, 2017

[10] L. A. Dissado, J. C. Fothergill, 'Electrical degradation and breakdown in polymers' IET, 1992.

[11] M. G. González, J. Baselga, J. C. Cabanelas, 'Applications of FTIR on epoxy resins-identification, monitoring the curing process, phase separation and water uptake', INTECH Open Access Publisher, 2012.

[12] E. Yousif, R. Haddad, 'Photodegradation and photostabilization of polymers, especially polystyrene: review', SpringerPlus, 2(1): 398, 2013

[13] K. Pielichowski, J. Njuguna, 'Thermal degradation of polymeric materials', Rapra Technology, 2005.

[14] M. Z. H. Makmud, Aulia, Y. Z. Arief and M. U. Wahit, 'Ageing and degradation mechanism of linear low density polyethylene-natural rubber composites due to partial discharge', IEEE International Conference on Power and Energy (PECon), Kota Kinabalu, 2012, pp. 985-989

[15] S. Bahadoorsingh and S.M. Rowland 'Investigating the Influence of the Lubricant Coating on Hypodermic Needles on Electrical Tree Characteristics in Epoxy Resin' IEEE Transactions on Dielectrics and Electrical Insulation, Vol. 17, Issue 3, pp. 701-708, 2010 